\title{
CYBERNETICS AND PRECURSORS OF PROMOTING CRITICAL THINKING - A WAY TO CHANGE THE SCHOOL
}

\author{
Teodora Surubaru and Dorin Isoc \\ GRAUR - Group for Reform and University Alternative, Cluj-Napoca, Romania
}

\begin{abstract}
The requirement to assure the teaching of critical thinking put the school in front of its own weaknesses. A profound criticism highlights limitations, hindrances and obstacles that are difficult to pass without the personal efforts of the teachers. Following criticism, one can identify a set of requirements that would allow for improvement and upgrading. This set of requirements builds the specification of a cybernetic system developed to help the training process promoting the critical thinking. The new cybernetic system diminishes the role of the teacher as coordinator in approaching the field of interest, inclusively the building of the recommended bibliographic list and interventions in crises. The main stages of the training sessions coordinated by the cybernetic system aim at a) building a set of problems by the students; b) the classification of all proposed problems according to their opportunity established by the voting group; c) solving the proposed problems by the students; d) evaluating, by vote, all the solutions offered for the proposed problems. Using the formulated specification and the established operating algorithm the operating scheme of the cybernetic system is being built. The proposed scheme is intended to monitor and manage the training process. The results interpretation highlights the absolute novelty of such a system and analyzes how it satisfies the original specification. One observes the generality of the concept, the way it meets the requirement of promoting critical thinking, the fact that the promotion is made gradually and continuously.
\end{abstract}

\section{KEYWORDS}

Training, Critical Thinking, Cybernetics, Criticism, Evaluation, Problem Building, Problem Solving

\section{INTRODUCTION}

The technological evolution of society, as well as of human relations, entails an increase in the degree of adaptation of the school. It is worth mentioning that the school is losing more and more of the training resources taken over by the electronic environment and other ways of training the workforce. All these resources and means have a significant influence on the student's future, the future specialist. Moreover, this influence isn't a uniform one neither on individuals nor on groups of individuals.

Thus, the school finds itself among many variables: the technological evolution determines the lack of specific knowledge and skills, the level of formal and informal learning of the student is always different and differs from individual to individual, the amount of information increases and changes its coordinates in the space training, at less and less frequent time periods.

In the school modernization strategy a key role is the choice of a higher standard. In this case, learning "critical thinking" seems to be a provocative ideal.

In this sense, the definition introduced by (Scriven and Paul, 1987) appears as a true specification of the notion. We note in particular that the achievement of the objective does not seem possible from a simple reform or maneuver on a long-standing social system, but the definition is a set of tangible in time sub-objectives.

„...critical thinking is the intellectually disciplined process of actively and skillfully conceptualizing, applying, analyzing, synthesizing, and/or evaluating information gathered from, or generated by, observation, experience, reflection, reasoning, or communication, as a guide to belief and action. In its exemplary form, it is based on universal intellectual values that transcend subject matter divisions: clarity, accuracy, precision, consistency, relevance, sound evidence, good reasons, depth, breadth, and fairness..." 
In fact, many references (Mandernach, 2006) (Saeed, 2012), (Snyder and Snyder, 2008) highlight realistically those hindrances that prevent the current school from reaching such an objective.

Together with other researchers, (Snyder and Snyder, 2008) emphasizes the role of questions and problems in addressing learning "critical thinking." However, there is a tendency to introduce surrogate solutions without fundamental changes to the conventional school, and also the tendency to keep the teacher at the heart of the concerns when it comes to school.

Far from reducing school to the mere accumulation of knowledge, it is undeniable that any training process begins and is a stage of acquiring knowledge. At this stage of training, it is essential how the teacher and the student are positioned and cooperate, how the relationships between the teacher and the group of students are.

The evolution of the school never changed the relationship between the teacher and the student, never changed their role in the training process. It may be possible to insist on some changes in the form in which these roles happen, and by accentuating new requirements such as creativity, which could be added to traditional tasks (Iba et al, 2011).

In this context, the emergence of software occurs as a revolution through the volume of resources and the new communication possibilities (Klamma et al, 2007). Still, however, the student-teacher relationship does not change in essence.

A more realistic vision on the school (Dewey, 2004) occurs when looking at the analysis of its purpose, the ability to stimulate thinking. In these situations, it quickly concludes that school is not the one that stimulates, but rather that, which inhibits thinking. When we talk more about school and the one that inhibits thinking, it is inevitable not to insist that it's the teacher. He/she is who can develop the ability to think or, on the contrary. He is the one who looks for the problems and assumes responsibility for the applied guidance on future results.

„....A large part of the art of instruction lies in making the difficulty of new problems large enough to challenge thought, and small enough so that, in addition to the confusion naturally attending the novel elements, there shall be luminous familiar spots from which helpful suggestions may spring..."

This latter conclusion is the one that puts the most important diagnosis on the school framework. In the traditional view, the teacher possesses and insists on arrogating the exclusivity of the right to know everything, to be the master of the problems and the victim of the solutions. The teacher is a victim because his/her problems almost never coincide with the real problems of the student.

The subject of this research is situated in the school area, of the necessity to systematically promote "critical thinking", the argumentation of some ways of intervention on the organization and functioning of the training process in order to make it more efficient for the benefit of the student and to materialize the requirements in a dedicated cybernetic system.

In the second chapter a criticism is made on some aspects of functional training systems. The finality of the critique is to identify the requirements of a specification of the interventions the author wishes to suggest and the cybernetic system to develop.

The third chapter introduces a set of principles that should underpin a cybernetic system. It is noteworthy that these principles take into account both the elements of specification introduced and the requirements that can build critical thinking. The criteria have a mixed pedagogical - technical - organizational structure.

The fourth chapter describes the functional scheme of the cybernetic system dedicated to the training process and its main working algorithm. Although succinctly, the presentation is sufficiently explicit to allow a series of consistent interpretations, further found in the fifth chapter. Interpretations emphasize how the proposed technical solution addresses the multiple requirements previously analyzed. Finally, in the conclusions chapter are synthesized those elements of contribution that are meant to solve the problem of critical thinking through the systematic generation of precursors.

The essential contribution of the article is its first coherent presentation of the elements of a complex cybernetic system that eliminates the teacher as a human factor responsible for the acquisition of critical thinking and replaces it with the group of all the students working under a procedure and under the control of the machine. The whole of the students is especially performing precisely because they are responsible for generating problems, but also for building solutions with reference to a segment of knowledge and reality judiciously chosen by the teacher. 


\section{A CRITICISM OF CONVENTIONAL TRAINING SYSTEMS}

In the following, the analysis of the current training system is carried out especially in terms of a technical system. Other, even interesting, aspects are approached only to the extent that they have consequences in the training technique.

Building a technical system, be it a socio-cybernetic system, requires a set of objectives and a fair reporting at a current context and stage.

Obviously, the training process has several component parts, but its destination is to ensure the acquisition of knowledge and skills. If acquiring skills involves a controlled exercise, when it comes to acquiring knowledge in school, the main form of current action involves passing it through lectures, university courses or assimilated forms. We will encompass all these forms of transmission of knowledge under the generic name of "training". In addition, the call to the name of "instructor" will also be generic for any quality of teacher or assimilated, and the same for the name of "student" for any person who is in a position to acquire knowledge systematically in an organized form based on a group of individuals.

Conventionally, the relationship between the instructor and the student assumes the student's interest, the instructor's competence and a volume of knowledge to assimilate by specific forms. The collaboration between the instructor and the student has also no other premises than the student's supposed interest.

A criticism of conventional training systems can only consider criteria that address their functionality.

\subsection{The Lack of Actuality and Efficiency of the Lecture Technique}

In (Isoc and Isoc, 2010) an analysis of the general relationship between the instructor and the student is made through the sources of knowledge and the way these sources affect the student's initial level of knowledge. The conclusion of the study is that, over time, the instructor has gradually lost the exclusivity of knowledge sources through the emergence of media vectors, such as radio, television, computer, internet.

The main consequence is that the initial level of knowledge of any subject with which the student comes to school is no longer void and differs from person to person. In this way, the effectiveness of the trainer's work is becoming relative. Under the same conditions, it is increasingly difficult for the school to meet the individualized requirements of each student.

\subsection{Lack of Personalized Training}

In general, training happens through groups and thus, all individual results are marked by the intrinsic nature of the quality of the student and his / her colleagues. Through quality of the student is also understood the volume and quality of knowledge acquired a priori by the student from the resources available to inform.

The student's individual quality and then, the quality of the student group affect the quality of the training. A student with better initial information will have a better evolution. Better initial student information will ease training, but at the same time, it will focus on certain topics, often different from the teacher's priorities.

Most often, the instructor is the one who presumes the student's needs and imagines his or her own ways to make his / her best presentation (Bergin, 2000).

One can thus talk about a lack of adjustment between the student's actual topics of interest and the topics of interest proposed by the instructor. As the student represents a certain vision of the labor market, the lack of adjustment becomes a potential conflict within the school between new and old, between useful and less useful.

The greater the distance between the students 'topics of interest and the themes of the instructors' interest, the less is the school's efficiency.

This identifies the need for adaptation between the instructor and his students as a way to improve the school. Practically, each student series can direct the instructor's activity to specific chapters of a common knowledge pool or to the need to enrich the knowledge base asked for the training. 


\subsection{Lack of Use of the Latent Potential of the Group of Students}

Conventional school puts the instructor in the core of its action. It is the classic vision and it has proven effective in historical times long gone. By repositioning the school's actors before the sources of knowledge, the process of "democratizing" the sources of knowledge, the role of the instructor decreases. Instead, the formative role of interaction within a group accentuates in front of a volume of knowledge.

Collaboration can thus gain more from the classical role of the instructor. Collaboration can be a natural solution to trigger the latent potential of the group of students. When it comes to engineering, for example, collaboration is not just a desideratum; it becomes a necessity imposed by the standards of the profession.

\subsection{The Difficulty of Acquiring "Critical Thinking"}

Defined within a desideratum, "critical thinking" is the one that has the lowest chances to be acquired in conventional school under the conditions of conventional education systems.

If we take only the conclusions of a single reference (Saeed et al, 2012), the conventional school represents, both in the form of organization in classes and through education instructors, a background incompatibility with "critical thinking" training.

We remember here (Snyder and Snyder, 2008) that there are sufficient evidences that "critical thinking" is not properly assessed in the context of the traditional school. Thus, the hindrances to inefficiency correctly identifies: a) lack of training of trainers, b) lack of information; c) preconceived ideas from both instructors and students; d) time constraints. It identifies further the need to increase the efforts of the instructor and the students' reaction as a point where they can intervene. Finally, the practical solution is given, namely, the questioning.

It is obvious that the lack of effects lies in the absence of a coherent project that justifies and further bases the intervention.

\subsection{Lack of Adaptation to the Needs of Lifelong Learning}

It is increasingly difficult to see a person's professional and social development without taking into account the need for lifelong learning. However, the achievement of continuous learning also implies some particular aspects. Their simple mention is found in any work in the field (Klamma el al, 2007). We remind them, as these issues relates to the subject.

There are discussions about the difference between adult learning and youth learning, about the difference between formal and in-formal learning, about collaborative learning platforms and their role in providing customized solutions.

\subsection{An Interpretation of Criticism - Specification of Modernization Intervention}

Because of the criticism, there are some conclusions that can offer new solutions for the modernization of the training process and the training structures.

Information technology becomes part of the training process not only by allowing access to information:

1. Training cannot ignore the diversity of students' initial levels of knowledge.

2. Training requires metering as objective as possible of indicators to properly relate the effects of training to the real needs of students.

3. Training needs to be the one that takes at the right moment new knowledge and sources of knowledge customized to the needs of society.

4. It is necessary for the instructor's activity to become more efficient in the process of coordinating the acquisition of knowledge.

5. It is unnatural that the instructor should support the entire quality of the school and the training.

6. The organizational and economic considerations of the training process cannot be ignored at any time. It is worth noting here indicators such as the size of the study groups, the achievement of an expected degree of satisfaction, the efficiency of the school in the areas of activity of the group of students in relation 
to the instructor. These indicators cannot be ignored in designing a training system.

7. Training has ceased to be an art. Training should be conducted in the area of efficient procedures from which information technology naturally belongs.

\section{PRINCIPLES OF MODERNIZATION INTERVENTION}

Here are some of the principles that will underpin the modernization of the training process. It is insisted that the purpose of the research is to build a socio-cybernetic system through which the school can better ensure "critical thinking".

\subsection{Critical Analysis Priority Principle}

The whole approach is based on the principle of critical analysis as a form of training development.

The essence of the principle describes with the recapture of the role of an instructor, which after Dewey, quoted in (Giles and Eyler, 1994) should be

,...to provide the materials and the conditions by which organic curiosity will be directed into investigations that have an aim and that produce results in the way of increase of knowledge, and by which social inquisitiveness will be converted into ability to find out things known to others, an ability to ask questions of books as well as of persons...".

During the implementation, the principle will be found in that the entire training process is based on the question or problem; and on the problem management task.

The question or problem is a lack of knowledge, explicitly expressed in relation to a volume of information suggested by the instructor. The complexity of the problem may be lower or higher. The way the problem is formulated is a free one and the only condition that is required is that the text of the problem is readable and understandable to any reader. The problems are read and evaluated firstly by the students.

\subsection{Principle of Priority of Interested Competence of Group}

Such a principle is introduced in the context of training and collaboration and occurs with reference to a group of people.

A possible statement of the principle of priority of interested competence could be:

Any action of a group of individuals interested in a joint activity is more competent than the action of any of its members considered separately.

Specifically, the training group consists, conventionally, of the instructor and the members of the student group. It will assume that if the group's professional opinion is permissible as a whole, then it manifests itself as a competence that is superior to the competence of each individual, so it is superior, including to the competence of the instructor.

Competence manifests itself in two ways. A first way is that in front of a problem formulated by a student, each member of the training group has all the conditions to provide a response, a solution.

On the other hand, competence will materialize in the fact that it is admitted that each member of the training group can give an appreciation of the degree to which a problem or a solution meets the needs of each individual. This appreciation is called the opportunity of the problem and the extent to which a solution offered for a problem is usable, will be called usability of the solution.

Expression of the individual position will be done through a quantitative vote expressed in different stages of the training process.

\subsection{Principle of Operational Constraints of Critical Action}

Professional training through specialized entities involves the presence of two less algorithmic features. It is about personal interest and the occurrence of synergy manifestations. 
Each feature in turn has a beneficial character and needs to be taken into account. Although these characteristics are also present in the conventional forms of the school, they are less exploited explicitly.

This time, the existence of a technical implementation allows the materialization of means by which the two characteristics become functional means.

|The personal interest will relate to the application of a mandatory action regime for certain stages of work and will be stimulated by the introduction of quantitative voting as a means of measurement.

Being a cybernetic system, the driven process is seen in its entire dynamic. It therefore seems natural to take into account that school, and the training takes place over time, and all the component parts that interact, including the training group and the instructor, act in time by means of own or imposed dynamics.

Constraints at the temporal variable have priority before other possible constraints.

\subsection{Principle of Objective Measurements in the Training Process}

Cybernetics produces controllable results only if the state of the controlled system is objective and reproducible. As state means a set of defined variables, the cybernetic system cannot exist outside of a state variables measurement subsystem.

\section{IMPLEMENTATION OF THE CYBERNETIC SYSTEM}

The effect of the connections and the proposed algorithm results from the description in Figure 1. The basic element of the socio-cybernetic system is the instructor-student relationship.

The instructor-student relationship is no $\backslash$ necessarily straightforward. However, the relationship always involves the existence of a motivation, of a specific interest for each party. It is to note that always the relationship has a procedural character. Conventionally, the relationship between the instructor and the student is an instructor-stimulated one.

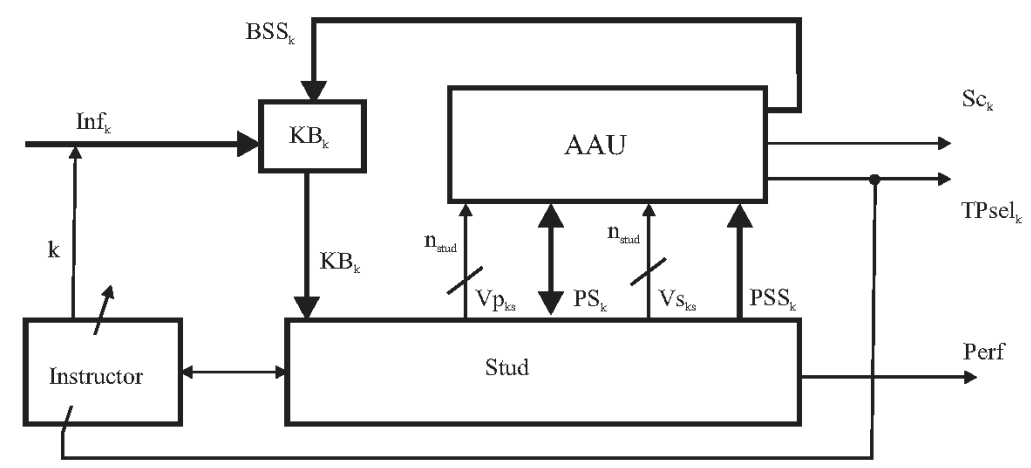

Figure 1. The block diagram of the self-adaptive socio-cyber training system

Without being explicit as such, the relationship between the instructor and the student responds to social desiderata, along with a series of individual desires of development and development of each student.

In the new vision, the instructor is the one who offers the training theme and then receives the request to adapt the training process from the group of students he is working with.

In the block diagram of Figure 1, one identifies $\operatorname{Inf_{k}}$ - the information planned for approach at time moment $k ; K B_{k}$ - the knowledge base built under the coordination of the instructor in order to support the training process; $S c_{k}$ - the set of opportunity degrees of the proposed problems and the usability degrees of the offered solutions; $T P_{s e l}$ - the set of unresolved problems at $k$ cycle; $B S S_{k}$ - the set of selected solutions to be introduced into the $K B_{k}$ knowledge base at the end of step $k ; A A U$ - the self-adapting unit; nstud - number of students of the working group; Stud - group of students in training activity; $P S_{k}$ - the set of problems generated by student activity in $k$-cycle of the self-adjusting system; $V p_{k s}$ - the qualifying votes of students for the proposed problems from step $k ; V_{s}$ - student votes to evaluate solutions for the problems proposed in step $k ; P S S_{k}$ - the set of solutions offered for the problems proposed by the students; Perf - the performance 
indicator of the training system. One insists that the solutions formulated by the students are also built by the action of the students.

The instructor's activity takes place over a time period in training sessions that correspond to cycles $k=1,2, \ldots$ In each work cycle, $k$, the instructor discusses an $I n f_{k}$ amount of information. Over time, in relation to the training process, a knowledge base, $K B_{k}$ for the $k$ cycle, also built on steps, can be identified.

$$
K B_{k}=K B_{k-1}+\operatorname{Inf} f_{k}
$$

The sequence of work stages, attached to each work cycle k, follows a step path described as in Algorithm 1.

Step 1: Students are provided, in co-operation with the instructor, with the information to be approached $\operatorname{Inf} k$.

Step 2: Each student is invited to formulate at least one problem with reference to work information.

Step 3: All students decide by vote on the degree of opportunity for each built problem.

Step 4: One builds the $P B_{k}$ problem base associated to $k$ step.

Step 5: Each student can offer solutions, $P S S_{k}$ for one or more of the built problems.

Step 6: Students decide by vote on the usability of each solution offered.

Step 7: The opportunity scores of the problems and the usability scores of the solutions from $k$ step are automatically integrated into the activity score of each student of the training group.

Step 8: Set of unresolved problems TPsel are given to instructor for priority treatment.

End of Algorithm 1

Algorithm 1. Work steps attached to each training $k$ cycle

\section{INTERPRETATIONS, DISCUSSIONS, RESULTS}

Although not specifically insisted, the proposed system is based on cybernetic principles. Among these principles, for this work, it is essential the providing of assistance and constant monitoring of the work of all actors involved.

By the provided algorithm of this system essential changes are produced in the structure and nature of the training process:

i. The instructor ceases to be the centre of the training activity. Its role diminishes to coordinate the themes to be addressed, to achieve the purpose of the training activity, and to intervene in special situations.

ii. By the nature of the built self-adaptive system, the problems become essential. Problems are formulated based on the training theme, without being limited by it. Students propose the problems without the teacher's influence.

iii. The problems suggested by the students reflect their real interest in the topic in question. The set of problems can be classified based on the interested competence principle and corresponds indirectly to the difficulty of the proposed problems.

iv. The students of training group offer solutions to the proposed problems. It should not be forgotten, that they have knowledge of the activity support given by the instructor. In this way, their solutions are built on their own perception.

v. The evaluation of the solutions offered to the proposed problems has as a criterion the usability related to the expectations and the interest of the students. The relevance of usability is ensured by the vote of all students who still respect once again the principle of interested competence.

vi. Turned into a coach, the instructor can rethink the "game schedule" after each training cycle. The "game scheme" involves associations of bibliographic references whereby topics of interest are covered as accurately and specifically as possible by the training group.

The proposed solution is not, in itself, a form, a mechanism for acquiring "critical thinking", but it is a possible collection of precursors to do that.

Once the system is used, there is the student's experience in addressing and refining the techniques of "critical thinking" development, such as the five steps of the IDEAS process suggested by (Facione, 1998). 
In the above, it should be added that both the texts of the problems and the texts of the solutions can be admitted only in written form and drafted according to norms that emphasize the stages of reasoning and context reporting.

One aspect worthy to be emphasized is that the "source of problems" is inexhaustible and is maintained in this state precisely by the freshness and lack of prejudice that any human being presents before a new theme in the absence of too many hindrances before the experience.

It emphasizes that achieving an electronic service from the developed cybernetic system eliminates the conventional school hours as the only condition is to ensure the transparency of the working stages and this is implicit.

One aspect of the experiments and simulations already carried out concerns the sizing of the training teams. It turns out that a number of 10-15 students per training group seem to be optimal. The limitation is not technical, but the optimization issue remains open and will probably be readjusted after a significant number of completed training sessions.

The principles outlined and how to conceive the cybernetic concept lie at the heart of the CyberTrainer training service.

\section{CONCLUDING REMARKS}

The extent of the requirements imposed on school, and in particular the imperative of promoting "critical thinking", highlighted the lack of adaptability of the traditional school. Following detailed functional analyzes, the obsolete role of the instructor confirms reported to the new conditions and the new requirements. Therefore, a specification of a training system is developed that could eliminate the persisting shortcomings.

The training system, based on cyber-grounds, shifts the role of the trainer to coach and focuses on successive modules of problem-building steps, followed by actions to classify their opportunity to the students of the training group, with steps to build solutions for these issues, followed by actions to evaluate built-in solutions. Students develop both, problems and solutions.

Suggested work is an operational precursor of "critical thinking" and has the consequence of involving the entire training group under the conditions of full transparency.

It is worth mentioning that with the monitoring and coordination of the training activity, the cybernetic system also has a module for integrating the students' activity scores on each cycle introduced.

The role of the instructor is limited to establishing the training plan and building the list of reference bibliographies.

The generalization of the cybernetic training system in a public service allows it to be extended from schools of all categories to continuous education activities, to specific training activities for elderly.

\section{REFERENCES}

Bergin, J., 2000, July. Fourteen Pedagogical Patterns. In EuroPLoP, pp.1-49.

Dewey, J., 2004. Democracy and education. Courier Corporation.

Facione, P.A., 1998. Critical thinking: What it is and why it counts. Retrieved June, 9, p.2004.

Giles Jr, D.E. and Eyler, J., 1994. The theoretical roots of service-learning in John Dewey: Toward a theory of service-learning. Michigan Journal of Community Service Learning, 1(1), p. 7.

Iba, T., et al, 2011, October. Pedagogical patterns for creative learning. In: Proceedings of the 18th conference on pattern languages of programs, p. 28.

Isoc, D., and Isoc, T., 2010, A new adaptive teaching method for engineering school. Journal Plus Education / Educaţia Plus. 6(2), pp. 124-131.

Klamma, R., et al, 2007. Social software for life-long learning. Educational technology \& society, 10(3), pp.72-83.

Mandernach, B.J., 2006. Thinking critically about critical thinking: Integrating online tools to promote critical thinking. Insight: A collection of faculty scholarship, 1, pp.41-50.

Saadé, R.G., et al, 2012. Critical thinking in E-learning environments. Computers in Human Behavior, 28(5), pp.1608-1617.

Snyder, L.G. and Snyder, M.J., 2008. Teaching critical thinking and problem solving skills. The Journal of Research in Business Education, 50(2), p.90. 